\title{
New estimates for Io eruption temperatures: Implications for the interior
}

\author{
Laszlo Keszthelyi ${ }^{\text {a,*}}$, Windy Jaeger ${ }^{\text {a }}$, Moses Milazzo ${ }^{b}$, Jani Radebaugh ${ }^{c}$, Ashley Gerard Davies ${ }^{\mathrm{d}}$, \\ Karl L. Mitchell ${ }^{\mathrm{d}}$ \\ a Astrogeology Team, U.S. Geological Survey, 2255 N. Gemini Dr., Flagstaff, AZ 86001, USA \\ ${ }^{\mathrm{b}}$ Lunar and Planetary Laboratory, University of Arizona, 1629 E. University Dr., Tucson, AZ 85721, USA \\ ${ }^{\mathrm{c}}$ Department of Geological Sciences, Brigham Young University, Provo, UT 84602, USA \\ d Jet Propulsion Laboratory, California Institute of Technology, 4800 Oak Grove Dr., Pasadena, CA 91109, USA
}

Received 30 January 2007; revised 19 July 2007

Available online 29 August 2007

\begin{abstract}
The initial interpretation of Galileo data from Jupiter's moon, Io, suggested eruption temperatures $\geqslant 1600^{\circ} \mathrm{C}$. Tidal heating models have difficulties explaining Io's prodigious heat flow if the mantle is $>1300^{\circ} \mathrm{C}$, although we suggest that temperatures up to $\sim 1450{ }^{\circ} \mathrm{C}$ may be possible. In general, Io eruption temperatures have been overestimated because the incorrect thermal model has been applied. Much of the thermal emission from high-temperature hot spots comes from lava fountains but lava flow models were utilized. We apply a new lava fountain model to the highest reported eruption temperature, the SSI observation of the 1997 eruption at Pillan. This resets the lower temperature limit for the eruption from $\sim 1600$ to $\sim 1340^{\circ} \mathrm{C}$. Additionally, viscous heating of the magma may have increased eruption temperature by $\sim 50-100^{\circ} \mathrm{C}$ as a result of the strong compressive stresses in the ionian lithosphere. While further work is needed, it appears that the discrepancy between observations and interior models is largely resolved.
\end{abstract}

(C) 2007 Elsevier Inc. All rights reserved.

Keywords: Io; Volcanism; Interiors

\section{Introduction}

Io, the innermost of Jupiter's four large moons, remains the only known extraterrestrial example of active high-temperature volcanism. One of the major discoveries from the Galileo Mission was that this volcanism is primarily silicate, although secondary volcanism involving sulfurous compounds does exist (McEwen et al., 1997, 1998a). Over 500 young volcanic centers, including $>150$ active hot spots, were documented (Schenk et al., 2001; Radebaugh et al., 2001; Lopes et al., 1999, 2004). The composition of the silicate volcanism is uncertain, but has been proposed to be ultramafic because of inferred eruption temperatures significantly above the $\sim 1200^{\circ} \mathrm{C}$ typical of terrestrial basalts (McEwen et al., 1998b). Table 1 lists all of the reported Ionian eruption temperatures over $1200^{\circ} \mathrm{C}$. Temperature estimates combining data from the

\footnotetext{
* Corresponding author. Fax: +1 9285567014.

E-mail address: laz@usgs.gov (L. Keszthelyi).
}

Solid State Imager (SSI) camera and the Near Infrared Mapping Spectrometer (NIMS) with a lava flow thermal emission model suggest at least one eruption with lava $\geqslant 1600^{\circ} \mathrm{C}$ (e.g., McEwen et al., 1998b; Davies et al., 2001).

It is somewhat surprising that only a handful of ionian eruptions have reported temperatures greater than the $\sim 1200^{\circ} \mathrm{C}$ (Table 1). This is apparently due to the sparseness of the high spatial and spectral resolution data that are needed to tightly constrain eruption temperatures. While there are complications from colorful sulfur-rich deposits, spectral data from the dark lavas show no evidence for compositional variations in the silicate materials. Instead, every dark deposit appears to contain the same very Mg-rich orthopyroxene (Geissler et al., 1999), so it is likely that actual eruption temperatures are quite uniform. It is noteworthy that most of the values in Table 1 are only lower limits. Therefore, the singularly high temperature estimate from the June, 1997 eruption at Pillan could actually indicate the typical eruption temperature for ionian silicate volcanism. 
Table 1

Previously reported ionian eruptions with temperatures $>1200^{\circ} \mathrm{C}$

\begin{tabular}{|c|c|c|c|c|}
\hline Eruption & Date & Instrument $^{\mathrm{a}}$ & Model eruption temperature & Reference \\
\hline$\sim$ North Pole & 06ОСТ1996 & IRTF NSFCAM & $\geqslant 1430{ }^{\circ} \mathrm{C}^{\mathrm{b}}$ & Stansberry et al. (1997) \\
\hline \multirow[t]{2}{*}{ Kanehekili } & 03APR1997 & Galileo SSI & $\geqslant 1270^{\circ} \mathrm{C}^{\mathrm{b}}$ & McEwen et al. (1998b) \\
\hline & 06MAY1997 & Galileo SSI & $\geqslant 1210^{\circ} \mathrm{C}^{\mathrm{b}}$ & McEwen et al. (1998b) \\
\hline \multirow[t]{2}{*}{ Pillan } & 28JUN1997 & Galileo SSI+NIMS & $\sim 1600^{\circ} \mathrm{C}^{\mathrm{c}}$ & Davies et al. (2001) \\
\hline & 08NOV1997 & Galileo SSI & $\geqslant 1260^{\circ} \mathrm{C}^{\mathrm{b}}$ & McEwen et al. (1998b) \\
\hline Marduk & 08NOV1997 & Galileo SSI & $\geqslant 1300^{\circ} \mathrm{C}^{\mathrm{b}}$ & McEwen et al. (1998b) \\
\hline \multirow[t]{4}{*}{ Pele } & 29DEC2000 & Cassini ISS & $\geqslant 1350^{\circ} \mathrm{C}^{\mathrm{b}}$ & Radebaugh et al. (2004) \\
\hline & 16OCT2001 & Galileo SSI & $\geqslant 1250^{\circ} \mathrm{C}^{\mathrm{d}}$ & Radebaugh et al. (2004) \\
\hline & 22FEB2000 & Galileo NIMS & $\geqslant 1280^{\circ} \mathrm{C}^{\mathrm{d}}$ & Lopes et al. (2001) \\
\hline & 20JUL1998 & Galileo SSI+NIMS & $\sim 1250{ }^{\circ} \mathrm{C}^{\mathrm{c}}$ & Davies et al. (2001) \\
\hline Tvashtar & 22FEB2000 & Galileo SSI & $\geqslant 1200^{\circ} \mathrm{C}^{\mathrm{b}}$ & Milazzo et al. (2005) \\
\hline
\end{tabular}

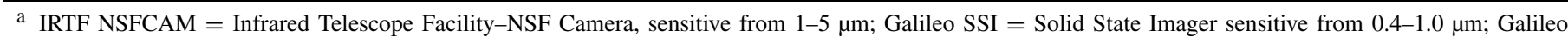
NIMS = Near Infrared Imaging Spectrometer sensitive from 0.7-5.2 $\mu$ m; Cassini ISS = Imaging Sub System, sensitive from 0.4-1.0 $\mu$ m.

b Unresolved hot spot; assumes eruption temperature is $\geqslant 200{ }^{\circ} \mathrm{C}$ above the measured color temperature.

c Fit to combined SSI and NIMS data.

d Select group of pixels from image that resolves the hot spot.

The nature of this volcanism has profound implications for the interior of Io. However, to date, no clear picture of Io's mantle has emerged from the analysis of the Galileo data. The prediction that Io has been extensively differentiated by magmatic activity (Keszthelyi and McEwen, 1997a) was disproved by eruption temperatures well in excess of $1100^{\circ} \mathrm{C}$. The straightforward interpretation of the high eruption temperatures is that Io's interior is largely molten (Keszthelyi et al., 1999, 2004). However, a molten Io is not viscous enough to generate the observed heatflow of $\sim 10^{14} \mathrm{~W}$ (e.g., Veeder et al., 1994) via tidal dissipation (e.g., Ross and Schubert, 1985). More recent models that couple the tidal heating to volcanic heat loss suggest that the interior should be no more than $20 \%$ molten (e.g., Moore, 2001). This, in turn, suggests a maximum magma temperature $<1300^{\circ} \mathrm{C}$ (Fig. 1).

The goal of this study is to solve this $>300^{\circ} \mathrm{C}$ discrepancy between the observational and theoretical constraints. We begin by examining the assumptions in the theoretical models. We then re-evaluate the uncertainties in the methods used to derive the temperature estimates and in the Galileo observations themselves.

\section{Reevaluating the models for Io's mantle}

All the models for Io's interior must make assumptions about its bulk composition. In general, it has been assumed that Io, like the rest of the Solar System, is broadly chondritic. Io's bulk density of $3527.8 \pm 2.9 \mathrm{~kg} / \mathrm{m}^{3}$ (Anderson et al., 2001) is consistent with such a bulk composition, though lower density chondrites are somewhat preferred (Kuskov and Kronrod, 2001). However, when the preliminary analyses of the Galileo data suggested eruption temperatures $>1700^{\circ} \mathrm{C}$, the possibility that Io has a highly exotic bulk composition had to be seriously entertained (Kargel et al., 2003; Schaefer and Fegley, 2004). In particular, it was hypothesized that lavas exposed to vacuum at these temperatures would put silicon and other elements into the gas phase, allowing the entire body to gradually evolve toward the composition of refractory calcium-aluminum inclu-

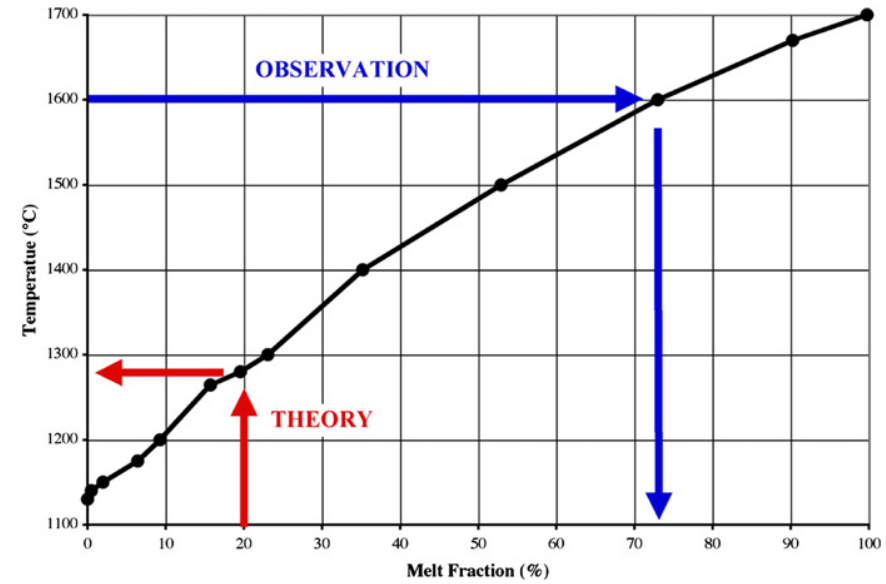

Fig. 1. Melting curve for the top of Io's mantle. Computed using the MELTS program (Ghiorso and Sack, 1995), a composition based on a CM chondritic bulk Io with a core and crust removed (Table 2), a pressure of $500 \mathrm{MPa}$ (Jaeger et al., 2003), and an oxygen fugacity $2 \log$ units below the QFM buffer (McKinnon, 2004). The observations suggesting $\sim 1600^{\circ} \mathrm{C}$ eruption temperatures (e.g., McEwen et al., 1998a; Davies et al., 2001) imply $>70 \%$ melting of the upper mantle. However, published theoretical models constrain Io's mantle to less than $20 \%$ melt (e.g., Moore, 2001) and suggest that eruption temperatures should not exceed $1300^{\circ} \mathrm{C}$. Resolving this $>300^{\circ} \mathrm{C}$ discrepancy is the focus of this study.

sions (CAIs) found in chondrules (Kargel et al., 2003). While an innovative hypothesis, we feel it is extremely unlikely given how quickly lava surfaces cool. Schaefer and Fegley (2004) show that vapor-phase differentiation of major rock forming cations (e.g., $\mathrm{Si}, \mathrm{Al}, \mathrm{Fe}, \mathrm{Mg}, \mathrm{Ca}$ ) will be effective if, and only if, the silicate surface is at $>1600^{\circ} \mathrm{C}$ and exposed to a pressure of order $10^{-3}$ to $10^{-4} \mathrm{~Pa}$. However, only $\sim 1 \%$ of Io is covered with active lavas (McEwen et al., 1985) and less than 1\% of even the most active eruptions are near the eruption temperature (e.g., Davies et al., 2001). Therefore, only volatile elements (e.g., $\mathrm{H}, \mathrm{C}, \mathrm{O}, \mathrm{S}, \mathrm{Cl}$ ) are expected to be substantially affected by vapor-phase differentiation.

An alternative way to estimate the evolution of Io's bulk composition in response to volatile loss is to extrapolate from 
current conditions. Io currently looses about $1000 \mathrm{~kg} / \mathrm{s}$ to space, but this is dominantly sulfur and oxygen (e.g., Spencer and Schneider, 1996). Using the composition of the Io torus as a rough guide (Spencer and Schneider, 1996), roughly $10 \mathrm{~kg} / \mathrm{s}$ of sodium is being lost, and much smaller amounts of other elements, such as potassium and chlorine. At current rates, Io would have lost only about $10 \mathrm{ppm}$ of sodium over 4 billion years. While losses may have been higher in the past; and while Io has clearly lost large amounts of lighter elements such as $\mathrm{H}, \mathrm{C}$, and $\mathrm{S}$; it is very unlikely that Io has lost a significant fraction of any of the elements that play a major role in anhydrous mantle mineralogy.

Determining Io's bulk composition to better than "broadly chondritic" is difficult. Consolmagno (1981) and Lewis (1982) suggested that CM chondrites would be a reasonable choice, considering both the likely composition of the materials condensing close to Jupiter and the lack of water and more volatile compounds on Io. On the other hand, Kuskov and Kronrod (2001) suggest that LL chondrites would be a better fit to the bulk density of Io. While these and other chondritic compositions are viable, Keszthelyi et al. (2004) showed that this level of refinement of the bulk composition of Io is not necessary for the discussions that follow. We will use the CM chondrite composition used in Keszthelyi and McEwen (1997a) here. While melting temperatures may vary by tens of degrees from the baseline composition we use, reasonable alternative bulk compositions cannot explain the $300{ }^{\circ} \mathrm{C}$ discrepancy we seek to explain.

How robust is the theoretical limit of $<20$ vol\% melt in the Ionian mantle? An upper limit on the melt fraction can be derived from the minimum viscosity and rigidity of the mantle that will allow the observed $\sim 10^{14} \mathrm{~W}$ to be generated by tides (e.g., Fischer and Spohn, 1990; Moore, 2003). If there is too much melt, the mantle is simply too fluid to dissipate enough energy. It is noteworthy that the timescale of interest is that of the tides (i.e., hours), not the $>1000$ years considered in most mantle convection models or the fractions of seconds sensed by seismic studies. Instead, the timescale is comparable to lava flow emplacement. While a lava flow begins to behave like a solid after $\sim 50 \%$ solidification (e.g., Marsh, 1981), it does not really lose its fluid nature until $\sim 75 \%$ solidification (e.g., Pinkerton and Stevenson, 1992). Similarly, $\sim 25 \%$ partial melting is required before a rock will "disaggragate" under stress (Moore, 2003). It seems safe to conclude that, only a small part of Io's mantle can contain more than $\sim 25 \%$ melt (e.g., Moore, 2003). While Io cannot be largely molten, it must have a substantial asthenosphere that is above the solidus (e.g., Segatz et al., 1988; Fischer and Spohn, 1990; Moore, 2003). If the mantle is completely solid, it will not dissipate sufficient tidal heat to drive the observed volcanism.

Maximum tidal dissipation takes place when the mantle has high rigidity but low viscosity. This can be understood by looking at Io as a viscoelastic fluid, with a viscous and an elastic component. The simplest example is called a Maxwell model with a spring (elastic) and a dashpot (viscous) connected in series. If the spring is weak and the dashpot is stiff, most of the deformation will be taken up in the spring. This will lead to little viscous dissipation. On the other hand, if the spring is stiff and the dashpot is fluid, the motion will be predominantly taken up by the dashpot where the viscous dissipation occurs. Of course, real rocks do not allow all choices of viscosity and rigidity.

While the viscosity of mantle rocks decreases in a relatively steady and monotonic way with increasing temperature, the rigidity has a sharp break at a "characteristic" temperature (Fischer and Spohn, 1990). Thus, maximum heating within Io would take place if the entire mantle were at this characteristic temperature. The numerical models agree that Io is close to, but not at, this peak efficiency (e.g., Segatz et al., 1988; Moore, 2003). Recent models find that it is more likely that Io is somewhat hotter than the characteristic temperature (Fischer and Spohn, 1990; Moore, 2003).

Laboratory experiments on partially molten mantle rocks show that the sudden decrease in rigidity takes place at 3-10\% partial melting, with a strong dependency on grain size (e.g., Kohlstedt and Zimmerman, 1996). The laboratory studies investigated a wide range of grain sizes, but for the most likely mantle conditions, the sharp drop in rigidity should take place at 5-7\% partial melting (Zimmerman and Kohlstedt, 2004). We conclude that some substantial portion of Io's mantle is more than $3 \%$ molten, and likely $>5 \%$ liquid. The minimum thickness of this partially molten layer in Io's mantle is a few tens of kilometers (Segatz et al., 1988), but partial melting distributed throughout the entire mantle is also allowed (Fischer and Spohn, 1990).

We conclude that only a small fraction of Io's mantle can have $>25 \%$ partial melting, but a substantial portion is $>3 \%$ molten. Because the solidus temperature increases relatively rapidly with pressure, this implies that the top of the mantle has the most melting. While different in many details, the idea of substantial melting in the ionian upper mantle is broadly consistent with other studies (e.g., Ross and Schubert, 1985; Segatz et al., 1988; Fischer and Spohn, 1990; Keszthelyi et al., 1999, 2004; Moore, 2001, 2003).

However, this melt distribution as a function of depth is rejected by Monnereau and Dubuffet (2002). Based on a numerical mantle convection model, they conclude that the melting of the mantle is limited to a small amount near the core-mantle boundary. This result appears to be an artifact of the limitations of their model. The most serious problem is that the model contains only one phase. Consequently, the hot solid mantle flows out onto the surface and cools to deep space. In reality, what happens is that only the melt (typically $\sim 2-20$ vol\%) escapes from the mantle and erupts to the surface. This process leaves the bulk of the hot (solid) rock behind in the mantle. In the Monnereau and Dubuffet (2002) model, the flow of hot rock out of the mantle is matched by cold crust flowing into the mantle, so the fact that the volume of material being extruded is being overestimated by a factor of 5-50 leads to the influx of cold rock being likewise overestimated by the same factor. Another important point is that the model assumes that tidal heating is distributed uniformly within the mantle. However, it is known that the deformation of the mantle decreases rapidly with depth and therefore the viscous dissipation also has a strong tendency to decrease rapidly with depth. Since their model greatly over- 
Table 2

Model compositions for MELTS runs

\begin{tabular}{lrrrr}
\hline Oxide & \multicolumn{1}{c}{ CM } & Bulk silicate Io & Crust & Mantle \\
\hline $\mathrm{SiO}_{2}$ & 35.65 & 44.24 & 47.29 & 44.06 \\
$\mathrm{TiO}_{2}$ & 0.13 & 0.16 & 0.60 & 0.13 \\
$\mathrm{Al}_{2} \mathrm{O}_{3}$ & 2.82 & 3.53 & 11.41 & 3.06 \\
$\mathrm{Fe}_{2} \mathrm{O}_{3}$ & & 1.87 & 2.67 & 2.01 \\
$\mathrm{Cr}_{2} \mathrm{O}_{3}$ & 0.54 & 0.68 & 0.00 & 0.72 \\
$\mathrm{FeO}$ & 30.34 & 14.40 & 15.58 & 14.14 \\
$\mathrm{MnO}$ & 0.27 & 0.33 & 0.26 & 0.33 \\
$\mathrm{MgO}$ & 24.99 & 31.01 & 9.11 & 32.22 \\
$\mathrm{CaO}$ & 2.37 & 2.95 & 8.64 & 2.61 \\
$\mathrm{Na}$ & 0.73 & 0.90 & 3.95 & 0.72 \\
$\mathrm{~K} 2 \mathrm{O}$ & 0.09 & 0.11 & 0.49 & 0.09 \\
$\mathrm{NiO}$ & 2.05 & 0.00 & 0.00 & 0.00 \\
vol\% of Io & 100 & 86 & 5 & 81 \\
\hline
\end{tabular}

estimates the cooling at the top of the mantle, and overestimates the heating at the base, their (erroneous) conclusion that melting is restricted to the core mantle boundary is understandable.

We use MELTS to search for the conditions that produce a mantle that (a) does not have large portions with $>25 \%$ melting and (b) has a significant fraction of the mantle with $\sim 5-10 \%$ melt. MELTS is a numerical program that utilizes fits to thermodynamic properties to calculate the equilibrium assemblage of minerals (and melt) at a given bulk composition, pressure, temperature, and oxygen fugacity. It has been tested against $>2500$ laboratory experiments and is particularly well calibrated for typical mantle and chondritic compositions (Ghiorso and Sack, 1995; Asimow and Ghiorso, 1998).

As in Keszthelyi and McEwen (1997a), we begin with the bulk composition of Io and remove the core to estimate the bulk silicate composition of Io. The core is known to be approximately $1000 \mathrm{~km}$ in radius (and $20 \mathrm{wt} \%$ of Io) (e.g., Anderson et al., 2001). We assume that the core is at a composition close to the $\mathrm{Fe}-\mathrm{FeS}$ eutectic, which has $\sim 5 \mathrm{wt} \%$ sulfur. We also assume that all the nickel is in the core. This means that the core contains enough $\mathrm{Fe}-\mathrm{Ni}$ to make up $15 \mathrm{wt} \%$ of Io. This composition is the one used in Keszthelyi and McEwen (1997a).

We estimate the composition of the mantle by removing a $30-\mathrm{km}$-thick crust formed by $25 \%$ melting of bulk silicate Io at $0.5 \mathrm{GPa}$ by iterative MELTS runs. The pressure and crustal thickness used here are based on models of the lithosphere as constrained by observations of ionian mountains (e.g., Jaeger et al., 2003). This composition is assumed to be that of the crust, which makes up about $5 \mathrm{vol} \%$ of Io. We remove this crust from the bulk silicate Io to give us an estimated mantle composition, as shown in Table 2.

In principle, magmatic activity could lead to further differentiation of the crust and mantle. Incompatible elements (such as $\mathrm{K}, \mathrm{P}, \mathrm{Ba}, \mathrm{Rb}, \mathrm{Na}, \mathrm{Sr}$, and $\mathrm{U}$ ) would be concentrated into a low density crust composed of the low melting temperature fractionates. Conversely, the mantle will be build up a concentration of high-melting temperature magnesian mafic minerals. Could the extremely active volcanism on Io indicate that the mantle is so refractory that only high temperature melts are to be expected? Keszthelyi and McEwen (1997a) examined this question and concluded that if there were no efficient

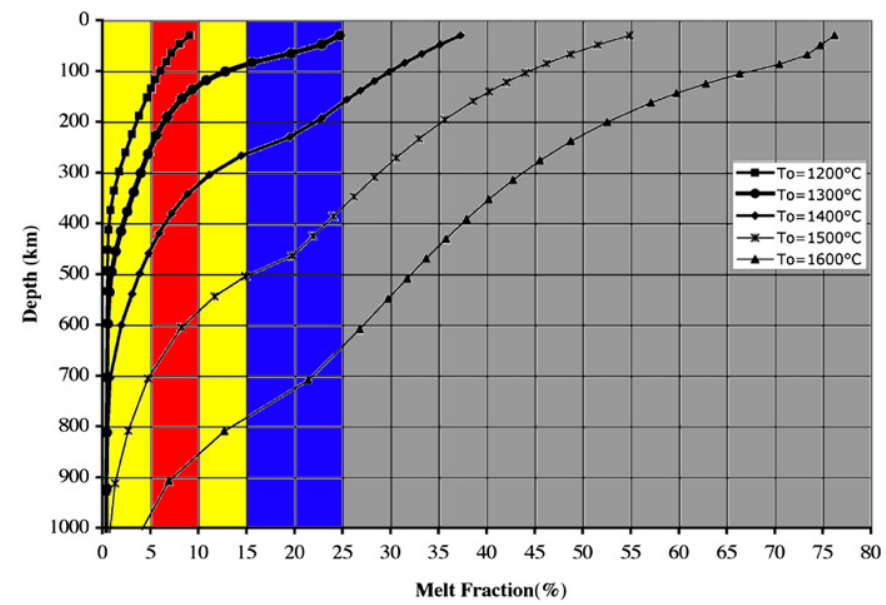

Fig. 2. Melt fraction as a function of depth and potential temperature. Assuming adiabatic rise, potential temperature is the same as eruption temperature $\left(T_{0}\right)$. Essentially no tidal heating should take place for melt fraction $>25 \mathrm{vol} \%$ (grey area) and little heating is expected in the 15-25 vol\% range (blue area). Peak efficiency for tidal heating is in the 3-10 vol\% range (red area), with 5-7 vol\% the most likely. Potential temperatures between 1200 and $1400{ }^{\circ} \mathrm{C}$ allow substantial tidal heating to drive the observed volcanism on Io.

means of recycling the crust into the mantle, we would actually see only relatively low temperature silicate volcanism on Io. This result is robust to a wide range of the assumed initial composition of Io, the amount of water it originally contained, and other variables. The fact that eruption temperatures in excess of $1100^{\circ} \mathrm{C}$ are observed requires that there be an efficient recycling mechanism and that there is limited differentiation between the crust and mantle (Keszthelyi et al., 1999, 2004). Therefore, the mantle composition in Table 2 should give us a reasonable working model. It is important to note that previous work (Keszthelyi and McEwen, 1997a; Keszthelyi et al., 2004) shows that the kinds of results we present in the following are very robust to the uncertainties in the original composition or the extraction of the core and crust.

Given this approximate mantle composition, we proceed to examine the range of plausible profiles through the mantle. We assume that the mantle is convecting and therefore the temperature profile will be adiabatic. We use a temperature gradient of $10^{\circ} \mathrm{C} / \mathrm{GPa}$ (e.g., Solomatov, 2000). Of course, to calculate actual temperatures, one also must fix the temperature at some pressure. The usual way of doing this is to provide the value at standard pressure (1 bar); this temperature is known as the "potential" temperature. We examine all potential temperatures between 1200 and $1600^{\circ} \mathrm{C}$, at $100^{\circ} \mathrm{C}$ intervals. For each potential temperature, we use MELTS to compute the equilibrium mix of minerals and melt at pressures ranging from 0.5 bar to $5.5 \mathrm{GPa}$ in 22 uneven steps $(0.1 \mathrm{GPa}$ between 0.5 and $1 \mathrm{GPa}, 0.2 \mathrm{GPa}$ between 1 and $3 \mathrm{GPa}$, and $0.5 \mathrm{GPa}$ between 3 and $5.5 \mathrm{GPa}$ ). The composition at $1 \mathrm{bar}$ is also computed, to have a reference at standard pressure. At each P, T point, MELTS outputs the different stable phases (solid minerals and melt) and gives their major element composition and thermo-physical properties (including density, entropy, enthalpy, heat capacity, and viscosity). Fig. 2 plots the melt fraction as a function of depth for the potential temperatures we examined. 
Fig. 2 graphically illustrates that if Io's mantle has a potential temperature $>1500^{\circ} \mathrm{C}$, then more than half the mantle (by volume) will be too molten to produce appreciable tidal heat. The greatest internal heating would take place if the mantle is $\sim 1250^{\circ} \mathrm{C}$ and reaches $\sim 15 \mathrm{vol} \%$ partial melting at the top. If Io is cooler than this, it is in an inherently unstable state that would drive it toward geologic quiescence: if Io cools, it will become less dissipative and heating will decrease. On the other hand, if Io has a potential temperature $>1250^{\circ} \mathrm{C}$, then if Io cools, it becomes more efficient at converting tidal energy into heat and warms back up. It seems more likely that Io is in this stable "hot" state (Moore, 2001).

Can the potential temperature of Io's mantle be better constrained than $1250-1500^{\circ} \mathrm{C}$ ? Limits have been calculated by estimating the rate at which melt is expected to escape from the mantle (Moore, 2001). If melt is removed faster than it can be produced (by tidal heating) then Io's mantle would cool and volcanism would shut down. Moore (2001) uses magma migration models to show that at $>20 \%$ melting magma leaves the mantle too quickly. However, Keszthelyi et al. (2004) show that by assuming that the average crystal size is $1 \mathrm{~mm}$, rather the $1 \mathrm{~cm}$ used by Moore (2001), >50\% partial melting is allowed.

While the ability of magma to move within the mantle does not place useful constraints on the state of the mantle, its ability to move from the mantle to the surface does. Io has a staggering rate of volcanism; if the observed heat loss were all provided by mafic lavas, $\sim 500 \mathrm{~km}^{3}$ would have to be erupted each year (Blaney et al., 1995) compared to $\sim 4 \mathrm{~km}^{3}$ per year for the Earth (e.g., Simkin and Siebert, 1994). In response to this high eruption rate, the crust must subside rapidly (e.g., O'Reilly and Davies, 1981) and thus be thrown into intense compression (Schenk and Bulmer, 1998). Assuming that the ionian crust is pervasively faulted, the stress at the base of a $\sim 30 \mathrm{~km}$ thick lithosphere could be as high as $\sim 0.5 \mathrm{GPa}$ (Jaeger et al., 2003). Pore fluids, such as liquid sulfur or sulfur dioxide, could reduce this value by lubricating faults (Kirchoff and McKinnon, 2003). However, sulfur dioxide is likely to be squeezed out of the rocks by a depth of approximately $10 \mathrm{~km}$ (Jaeger and Davies, 2006). Furthermore, for the nominal resurfacing rate of Io of $1 \mathrm{~cm} / \mathrm{yr}$ (Johnson et al., 1979; Spencer and Schneider, 1996), the melting temperature of sulfur would only be exceeded in the lowermost few kilometers of the lithosphere. Thus, the ability of fluids to lubricate faults is likely to be limited to a small part of the lithosphere and therefore not significantly reduce the expected compressional stress at the base of the lithosphere. In the unlikely event that the ionian faults are lubricated throughout the lithosphere, the compressional stress at the base of the lithosphere could be as low as $\sim 0.3 \mathrm{GPa}$.

In any case, these expected stresses are far in excess of the lithostatic pressure (which is only $\sim 0.15 \mathrm{GPa}$ for a crustal density of $2800 \mathrm{~kg} / \mathrm{m}^{3}$ and gravitational acceleration of $1.8 \mathrm{~m} / \mathrm{s}^{2}$ ) and poses a serious obstacle to magma ascent. In order for the magma to shoulder aside the lithosphere and rise to the surface, it must have $\sim 0.3-0.5 \mathrm{GPa}$ of buoyancy pressure. We use the earlier profiles through the mantle provided by MELTS to compute magma buoyancy pressure as a function of mantle po-

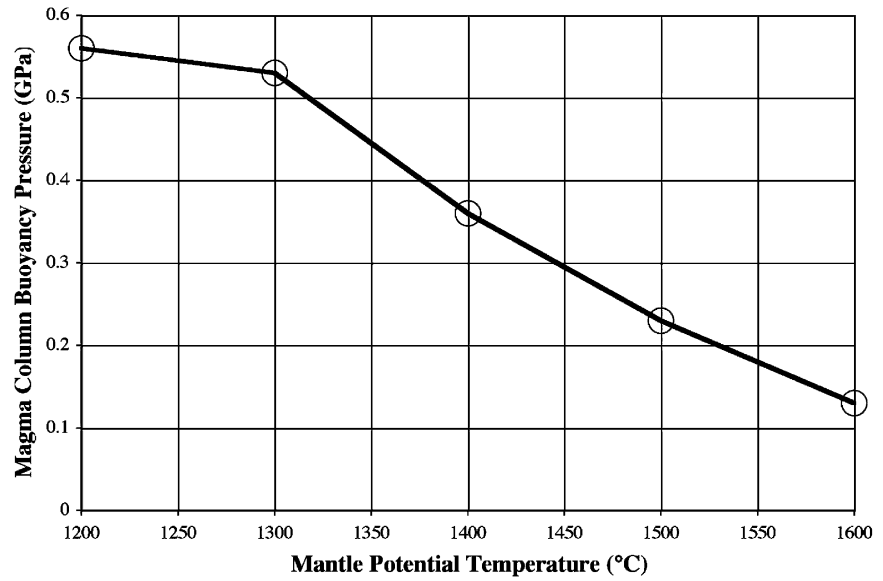

Fig. 3. Buoyancy pressure at the base of the lithosphere as a function of mantle potential temperature. Calculated from the melt fraction profiles shown in Fig. 2 and the density contrast between the melt and surrounding rock as given by MELTS. With increasing temperature, the density contrast between melt and rock is reduced, producing less integrated buoyancy pressure over the melt column.

tential temperature (Fig. 3). As noted earlier, amongst many other parameters, MELTS provides the density of the solid and liquid at each $P, T$ point shown in Fig. 2. The net buoyancy pressure at the base of the lithosphere can be calculated for each potential temperature by integrating

$\left(\rho_{\mathrm{s}}-\rho_{\mathrm{m}}\right) g \mathrm{~d} H$

from $H=$ the top of the mantle to $H=$ the bottom of the magma column, where $\rho_{\mathrm{s}}$ is the density of the solid, $\rho_{\mathrm{m}}$ is the density of the melt, $g$ is gravitational acceleration, and $H$ is height. An interconnected magma column is assumed to exist as long as (a) there is $>0.5 \mathrm{vol} \%$ melt (e.g., Kelemen et al., 1997) and (b) the depth is above the core-mantle boundary.

A direct reading of Fig. 3 indicates that the mantle potential temperature must be $\leqslant 1300-1450^{\circ} \mathrm{C}$ for volcanism to operate on Io. Uncertainties in this modeling are in the range of a few tens of degrees. We conclude that the potential temperature are likely to be $\sim 1300^{\circ} \mathrm{C}$ to overcome the average likely lithospheric compressive stress of $\sim 0.5 \mathrm{GPa}$, but may be somewhat hotter if lithospheric faults are significantly lubricated by pore fluids.

To summarize, our systematic review of models for Io's mantle conclude that the mantle potential temperature must be between $1250-1450^{\circ} \mathrm{C}$ with a preferred value $\sim 1300^{\circ} \mathrm{C}$. The top of the mantle is likely to be $20-30$ vol\% liquid with interconnected magma reaching down to $\sim 600 \mathrm{~km}$ depth. While there are multiple uncertainties of order $10^{\circ} \mathrm{C}$, the $\sim 300^{\circ} \mathrm{C}$ discrepancy between theory and observation is not resolved by a re-examination of interior models for Io.

\section{Reinspection of models for magma ascent}

If the theoretical predictions appear robust, we must ask if the observations have been properly interpreted. The first link we examine is if we can equate the eruption temperature to the mantle potential temperature. If the magma ascends adiabatically, it will cool only a few degrees during ascent. However, if 
other processes act on the ascending magma, the two temperatures can be decoupled. Previous work has rejected a number of mechanisms for heating the ascending magma (e.g., Kargel et al., 2003; Keszthelyi et al., 2004). These include (a) eruption from great depth/pressure, (b) tidal motion of the dike walls, and (c) electrical currents. However, we now find that the reasoning used to reject the idea of viscous dissipation during ascent was based on inappropriate application of terrestrial experience. Viscous dissipation in ascending magmas is generally negligible on the Earth, but may be important on Io because of the unique stress distribution within the ionian lithosphere. If the magma has sufficient buoyancy to overcome this compressional stress, it will ascend far faster than terrestrial magmas. We present a very simple model to quantify the viscous heating during ascent.

In an ideal 1-phase system, the viscous heating of the ascending magma can be equated to the work done on the moving fluid:

$Q_{\text {visc }}=\Delta P\left\langle v_{\mathrm{z}}\right\rangle / L$,

where $Q_{\text {visc }}$ is the heating rate per unit time, $\Delta P$ is the driving pressure, $\left\langle v_{z}\right\rangle$ is the average vertical speed of the magma in the dike, and $L$ is the vertical extent of the dike. Since rise time through the lithosphere is simply $L /\left\langle v_{z}\right\rangle$, the temperature increase of the magma $(\Delta T)$ can be expressed as

$\Delta T=\Delta P / \rho C$,

where $\rho$ is density and $C$ is the heat capacity. Because the magmas are expected to rise rapidly (even turbulently) through ionian dikes (Wilson and Head, 2001), heat loss by conduction through the wall rocks is negligible for reasonably wide dikes.

As discussed earlier, magma may have to counter as much as $0.5 \mathrm{GPa}$ at the base of the lithosphere, if the faults at that depth are not lubricated by pore fluids (Jaeger et al., 2003). However, since the magma ascends against gravity, the driving pressure would be only $\sim 0.34 \mathrm{GPa}$ (for a magma density of $2900 \mathrm{~kg} / \mathrm{m}^{3}$ and gravitational acceleration of $\left.1.8 \mathrm{~m} / \mathrm{s}^{2}\right)$. For a heat capacity typical of mafic magmas $(\sim 1000 \mathrm{~J} / \mathrm{kg})$, the predicted temperature rise would be $\sim 120^{\circ} \mathrm{C}$. If the faults are lubricated by pore fluids, the driving pressure could be as low as $\sim 0.14 \mathrm{GPa}$, resulting in a predicted heating of only $\sim 50^{\circ} \mathrm{C}$. For comparison, this computation predicts about $5{ }^{\circ} \mathrm{C}$ of cooling of a terrestrial basalt erupted from a typical magma chamber depth of about $5 \mathrm{~km}$ with only lithostatic driving pressure. This is in accord with the general lack of evidence of viscous heating in most terrestrial eruptions. It is the unique stress state of Io's lithosphere that allows the ascending magma to become superheated.

For the likely mantle potential temperature of $\sim 1300^{\circ} \mathrm{C}$, we predict an eruption temperatures close to $1400^{\circ} \mathrm{C}$. If the faults are lubricated, the lower compressional stress at the base of the lithosphere allows a hotter starting temperature $\left(\sim 1450^{\circ} \mathrm{C}\right)$, but less viscous heating $\left(\sim 50^{\circ} \mathrm{C}\right)$. Thus the eruption temperature could be as high as $1500^{\circ} \mathrm{C}$ if the faults are thoroughly lubricated, but this is unlikely. The gap between the theoretical upper limit and the reported lower limit for eruption temperatures is thus reduced to $\sim 200^{\circ} \mathrm{C}$, with uncertainties in the several tens of degrees.

\section{Improved eruption thermal model}

The next link to re-examine is the robustness of the methods used to extract eruption temperature from the observations. All the published eruption temperatures were calculated using thermal models specifically developed for lava flows. However, for most of the cases listed in Table 1, there is observational evidence for extensive lava fountaining.

At Pillan, the $\sim 400 \mathrm{~km}$ diameter new dark pyroclastic deposit is direct evidence of spectacular lava fountains (Williams et al., 2001; Davies et al., 2001). To produce this deposit, the active plume imaged over the Pillan eruption must have carried pyroclastics as well as gas. At Pele, the pattern of incandescence seen at high spatial resolution has been interpreted to indicate lava fountaining (e.g., McEwen et al., 2000; Radebaugh et al., 2004). Additionally, the fact that the thermal output of Pele is remarkably insensitive to the viewing geometry requires that the incandescent material have significant vertical extent, as in a fountain (Radebaugh et al., 2004). Similarly, the north polar eruption observed by Earth-based telescopes requires that the lava have significant vertical extent to be visible from Earth (Stansberry et al., 1997). In the case of Tvashtar, incandescent lava fountains $1-2 \mathrm{~km}$ tall were resolved in SSI images (McEwen et al., 2000; Milazzo et al., 2005).

Keszthelyi and McEwen (1997b) suggested that lava flow models could be applied to pyroclastic eruptions. However, when Milazzo et al. (2005) tested this suggestion, it became readily apparent that it was incorrect. The most serious problem is that the lava flow models assume that the lava is a semiinfinite half space. Small droplets of lava cool much faster than these models would predict. Here we present a very simple thermal model for lava fountains.

We take lunar pyroclastics to be a better analog to ionian pyroclastics than terrestrial examples because the Moon is more similar to Io. For example, the lack of appreciable atmosphere on the Moon and Io lead to very different fountain dynamics than on Earth, where bubble expansion is constrained the atmospheric pressure. Furthermore, the similarity in gravitational acceleration on the Moon and Io would assist in producing similar fountain dynamics. Finally, as will be shown later, the estimated eruption temperatures of the lunar and ionian eruptions are actually quite similar, suggesting broadly similar compositions and thermal histories for the pyroclasts.

Based on lunar pyroclastics, we expect the lava droplets to be $0.1-1 \mathrm{~mm}$ in radius (e.g., McKay et al., 1978). Such small droplets can be adequately modeled as isothermal spheres that cool by thermal radiation (e.g., Hopper et al., 1974; Klein and Uhlmann, 1976). The details of radiative heat transfer within a fountain are beyond the scope of this work. Instead, we make the assumption that the core of the fountain is optically thick and is maintained at the eruption temperature. Once a droplet leaves the core of the fountain, it is assumed to radiate to a background temperature. While the cooling is not very sensitive to the exact value of this background temperature, we select a value approaching the average surface temperature of Io, $-170^{\circ} \mathrm{C}$. With these simplifying assumptions, the cooling of a 


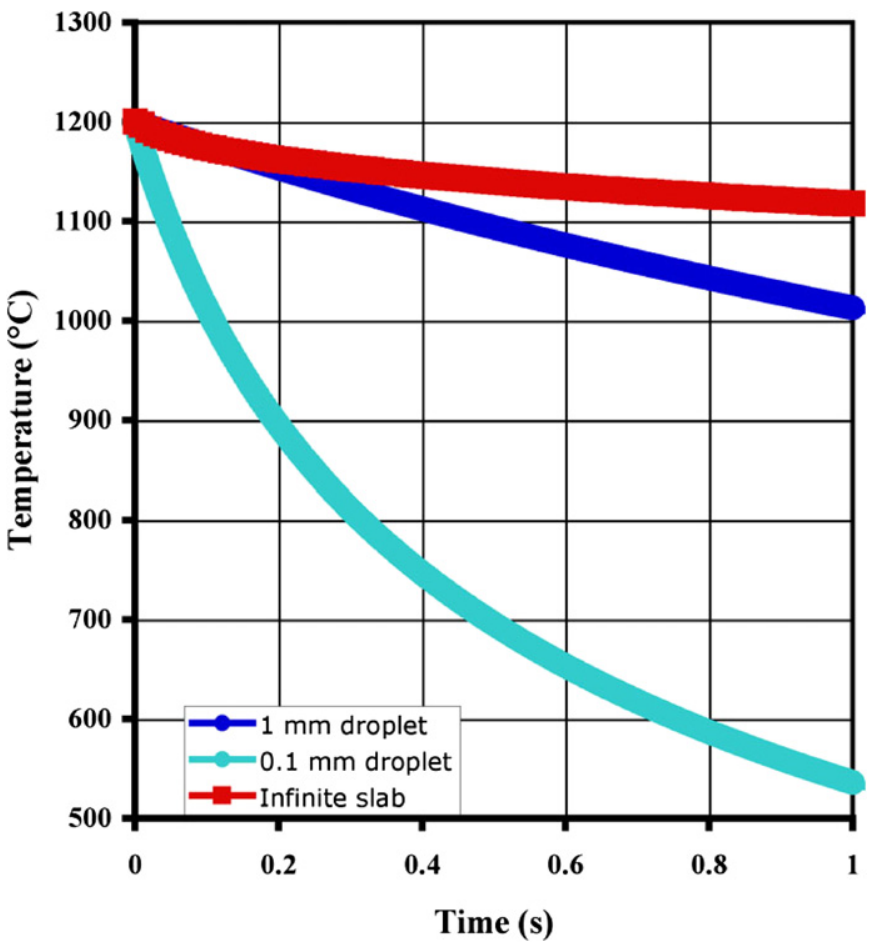

Fig. 4. Comparison of lava fountain and lava flow models. Curves show the 1st second of cooling from $1200^{\circ} \mathrm{C}$. As expected by intuition, small droplets cool much faster than a thick lava flow but larger droplets behave more like the lava flows. This can significantly affect the temperatures calculated from the observations of active eruptions on Io.

droplet is given by

$\mathrm{d} T / \mathrm{d} t=\sigma\left(T^{4}-T_{\mathrm{a}}^{4}\right) /(r \rho C)$,

where $T$ is the temperature of the droplet, $t$ is time, $\sigma$ is the Stefan-Boltzmann constant, $T_{\mathrm{a}}$ is the ambient temperature, $r$ is the radius of the droplet, $\rho$ is the density of the droplet, and $C$ is the heat capacity of the lava. Since the droplets should quench to glass, there is no latent heat of crystallization. To compute temperature as a function of time, $\mathrm{d} T / \mathrm{d} t$ is integrated over time. The result is closely fit by a function of the form $T(t)=c t^{-1 / 3}$ with the constant of proportionality $(c)$ controlled by the radius and thermal properties of the droplet. The divergence from a perfect fit disappears if the ambient temperature is absolute zero. Fig. 4 shows the dramatic difference in cooling for droplets versus a lava flow. This is to be expected since, as Howell (1997) demonstrated, the surface temperature of a cooling lava flow is approximately proportional to $t^{-1 / 8}$.

As long as the eruption is producing pyroclasts at a constant rate, the plot of temperature versus time (Fig. 4) is approximately the same as the distribution of temperatures captured in an image by remote sensing instruments. It is important to note that the droplets are likely to cool to ambient temperatures before they finish their ballistic flight. Wilson and Head (2001) provide a detailed analysis of the relatively small fountain seen in the November 1999 (I25) eruption at Tvashtar. The particles are estimated to be leaving the vent with about $500 \mathrm{~m} / \mathrm{s}$ of upward velocity. The total ballistic flight time $\left(t_{\mathrm{b}}\right)$ is given by

$t_{\mathrm{b}}=2 v_{0} / g$, where $v_{0}$ is the initial velocity and $g$ is gravitational acceleration (Milazzo et al., 2005). We estimate almost $10 \mathrm{~min}$ of flight for the droplets but Fig. 4 shows that they would cool below incandescence in seconds and reach ambient temperatures in $10 \mathrm{~s}$ of seconds. This is confirmed by the fact that the imaged incandescent fountains are only 360-900 m tall (Milazzo et al., 2005), corresponding to the initial few seconds of flight. If the pyroclasts did not cool in flight, then the temperature distribution in the fountain would be cut-off as the pyroclasts hit the ground.

If the fountain is not resolved, then the entire temperature distribution is contained within a single pixel. While fountains are generally not in steady state on timescales of minutes to hours, they are often steady over a period of seconds. Since the droplets cool below incandescent temperatures within seconds, the assumption of steady state for interpreting the SSI data should be relatively sound. Further work is needed to fully understand how fountains would appear to NIMS, which is able to detect much lower temperatures than SSI and thus must be concerned with variability over tens of seconds.

Even thought the fountain model we present is oversimplistic, it does provide some useful insight. We can quantify the predicted signal in a Galileo SSI image by convolving the known spectral response of the camera with the modeled temperature distribution. The detailed description of the SSI filters and their spectral responses can be found in Milazzo et al. (2005) and references therein. However, it is important to note that SSI's solid-state charge couple device (CCD) detector has a hard cutoff in response at wavelengths longer than about 1.1 microns. The effect of this is that the camera is completely blind to surfaces below $\sim 430^{\circ} \mathrm{C}$.

The other key consideration is that there are two different types of temperatures that can be measured by SSI. From single filter images, brightness temperatures can be calculated, if one makes can estimate how much of the pixel is filled with incandescent material. Commonly, it is simply assumed that the pixel is filled with a single temperature blackbody (e.g., McEwen et al., 1997). This assumption is usually very poor, so color temperatures, calculated from the ratio of images taken in two different filters, are preferable. Using data from different wavelengths allows both the incandescent area and a temperature can be calculated independently. One consequence is that color temperatures are completely insensitive to the size of the emitting body. This will be the key to explaining some counterintuitive results from the calculations that follow.

In order to convert the model temperature distribution (i.e., Fig. 4) to a predicted SSI response, first the integrated thermal radiation from the temperature distribution must be calculated. This is done numerically, as described in Milazzo et al. (2005). In this case, up to $10^{4}$ different droplet ages (i.e., temperatures) were included in the numerical integration. The thermal emission at each temperature was computed at 150 different wavelengths between 0.35 and 1.1 microns using the StefanBoltzman equation, assuming an emissivity of 1 . This blackbody emission was then multiplied by the filter transmissivity (a non-dimensional number with a value between 1 for completely transmitting and 0 for completely opaque). This value is 
then multiplied by the detector sensitivity at that wavelength, which converts the result from units of flux to electrons/per second generated on the detector. By summing over all the different wavelengths and temperatures, the integrated signal is obtained. This value then can be converted to instrument data number (DN) by multiplying by the exposure duration and the gain setting. In practice, it was found most practical to convert all SSI observations from DNs to units of electrons per second for thermal emission studies (e.g., McEwen et al., 1998b). Note that the summing over temperature uses the assumption that there is a constant rate of pyroclast formation, thus time and area are assumed to be related by a simple multiplicative constant with units of $\mathrm{m}^{2} / \mathrm{s}$. Since we deal with ratios in deriving color temperatures, this multiplicative constant cancels and is ignored in our calculations.

The integrated signal from fountains with eruption temperatures of $1200-1600^{\circ} \mathrm{C}$ were computed, to span the full range predicted by the earlier modeling of Io's interior. The vast majority of color temperatures derived from the SSI observations used the clear (CLR) filter (i.e., no filter) and the $968 \mathrm{~nm}$ or "1micron" (1MC) filter. Therefore we exclusively investigate the CLR/1MC color temperature for the Galileo SSI camera.

The relationship between the integrated signal from blackbodies at temperatures between about 300 and $1700^{\circ} \mathrm{C}$ and the corresponding CLR/1MC ratio has been previously established (e.g., Fig. 2 in McEwen et al., 1998b). We have found that the relationship between the blackbody temperature and the CLR/1MC ratio for the first part of the Galileo Mission can be well approximated by the following empirical fit:

$$
\begin{aligned}
T_{\mathrm{c}}= & -5.29 \times 10^{-5} R^{6}+4.89 \times 10^{-3} R^{5}-0.181 R^{4} \\
& +3.50 R^{3}-38.5 R^{2}+291 R-146,
\end{aligned}
$$

where $T_{\mathrm{c}}$ is the blackbody temperature and $R$ is the CLR/1MC ratio. As the SSI camera degraded with age, it was necessary to change its operating mode. The fit for the latter part of the mission is

$$
\begin{aligned}
T_{\mathrm{c}}= & 3.47 \times 10^{-5} R^{6}-3.17 \times 10^{-3} R^{5}+0.109 R^{4}-1.69 R^{3} \\
& +9.23 R^{2}+77.5 R+187 .
\end{aligned}
$$

As the discussion above shows, when we speak of a color temperature, we actually mean the blackbody temperature that would produce the same CLR/1MC ratio as we observe coming from the full temperature distribution. Note that since the CLR/1MC ratio cannot be less than 1, the empirical fits are incapable of producing a color temperature less than $110-272{ }^{\circ} \mathrm{C}$. The lack of observed ratios less than 3 (McEwen et al., 1998b) empirically confirms that SSI is blind to temperatures less than $\sim 460^{\circ} \mathrm{C}$.

We take the CLR/1MC ratios we calculate for the model fountains at each eruption temperature and then use the above empirical relationship to obtain the color temperature. When we plot the model eruption temperature versus the color temperature from the entire fountain, we find that a simple linear fit is appropriate (Fig. 5). For the early part of the mission the relationship can be given as

$T_{0}=1.25 T_{\mathrm{c}}-127$,

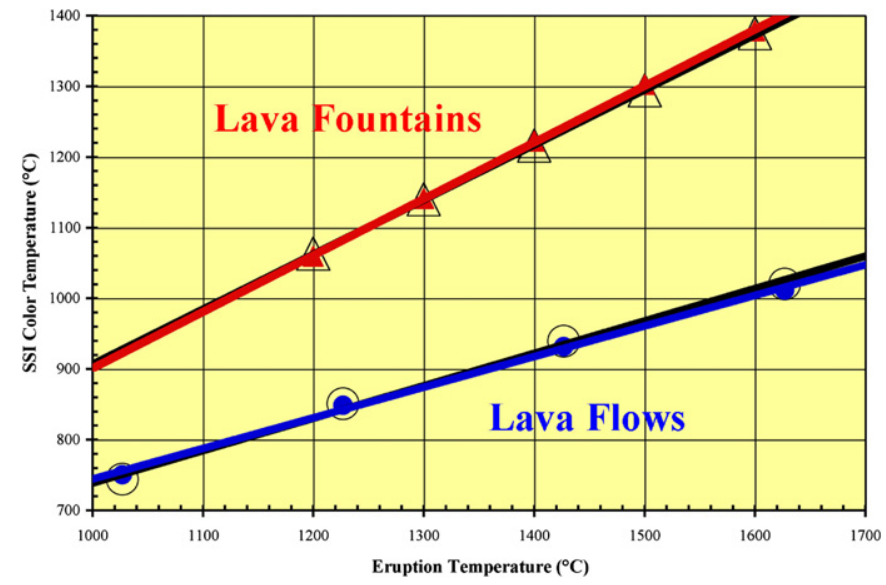

Fig. 5. SSI color temperature for lava fountain and lava flow models. Both thermal models assume that the full range of lava surface temperatures are found in a single pixel and that the lava cools by thermal radiation. The only difference is that the fountain thermal model assumes small isothermal droplets while the lava flow model assumes an infinite slab of lava. Red and blue symbols and lines are color temperatures calculated using the responses of the SSI clear (CLR) and $989 \mathrm{~nm}$ (1MC) filters in the early part of the Galileo Mission. Black symbols and lines use calibration from late in the mission.

where $T_{0}$ is the eruption temperature, and $T_{\mathrm{c}}$ is the color temperature calculated from the ratio of the fluxes through the SSI clear and 1 micron filters. Temperatures are expressed in ${ }^{\circ} \mathrm{C}$. This fit is valid for eruption temperatures between 1200 and $1600^{\circ} \mathrm{C}$. Using the calibration for the latter part of the mission, this changes slightly to

$T_{0}=1.29 T_{\mathrm{c}}-165$.

One counterintuitive result should be discussed. When the CLR/1MC ratios are calculated for a fixed eruption temperature but different pyroclast radii, the resulting plot of $T_{0}$ versus $T_{\mathrm{c}}$ is identical. This means that the color temperature is completely insensitive to the size of the droplets and thus the rate at which they cool. This apparently absurd result is the consequence of that fact that color temperatures are not affected by changing the size of the hot area. If one examines our simple lava fountain model, the proportion of droplets at any given temperature does not change when the droplet radius is changed. The amount of hot material, and thus the total flux is highly sensitive to the droplet size. But the shape of the temperature distribution is not. Of course, in a real fountain with a mix of particles sizes, this simplistic result will not be perfectly adhered to. Still, the fact that color temperatures rely on ratios, rather than absolute values, means that color temperatures are remarkably oblivious to many physical processes, and thus provide a robust estimate of the actual eruption temperature.

We repeat this entire exercise for lava flows. We use the thermal model described in Keszthelyi and McEwen (1997b) and used in Milazzo et al. (2005) to obtain the distribution of temperature versus time. This model assumes that the lava is an infinite half-space that cools by thermal radiation. It does include the temperature- and bubble-dependent thermal properties of the lava, as well as crystallization. We compute the CLR/1MC ratio by convolving the thermal emission with the SSI camera's wavelength-dependent response, using the assumption that the 
rate of lava production is constant. The ratios are converted to color temperatures and then color temperature is plotted against eruption temperature. This produces the following linear fit using the calibration for the early part of the mission

$T_{0}=2.31 T_{\mathrm{c}}-719$

and

$T_{0}=2.18 T_{\mathrm{c}}-613$

for the latter part. Fig. 5 shows these fits graphically and demonstrates that, for a given observed SSI color temperature, the lava flow model gives an eruption temperature about $500-600{ }^{\circ} \mathrm{C}$ higher than the lava fountain model.

If the values in Table 1 relied only on SSI color temperatures, the decrease in estimated eruption temperature from using the lava fountain model could more than explain the $300^{\circ} \mathrm{C}$ discrepancy between theory and observation. However, the highest temperature case in Table 1 is particularly complex. Therefore, we must continue to delve into the details of the previous data analyses.

\section{Reanalysis of uncertainties in the observations}

While many observations allow ionian eruptions above $1500{ }^{\circ} \mathrm{C}$, only one seems to require it: the 1997 eruption at Pillan. For Pillan, SSI and NIMS data were combined to place tight constraints on the allowable eruption temperature (Davies et al., 2001). In particular, the CLR/1MC ratio could not be fit without such high eruption temperatures. However, upon revisiting the Pillan SSI observation, we find that the uncertainties in the ratio can be refined.

The re-analysis hinges on the methodology for extracting the CLR/1MC ratio. The intent was to obtain both the CLR and $1 \mathrm{MC}$ data in the same image by (a) imaging through the $1 \mathrm{MC}$ filter for $25.6 \mathrm{~s}$ with Io on the left-hand side of the detector, then (b) closing the shutter, (c) moving the scan platform such that Io was on the right-hand side of the detector, (d) rotating the filter wheel to the CLR position, (e) opening the shutter, and (f) imaging through the CLR filter for $6.4 \mathrm{~s}$. Instead, the scan platform moved after only $13.8 \mathrm{~s}$. The result was a $13.8 \mathrm{~s}$ exposure through the $1 \mathrm{MC}$ filter on the left, a streak as the scan platform moved, and an image on the right that superimposed the remainder of the $1 \mathrm{MC}$ exposure and the $6.4 \mathrm{~s}$ CLR image (Fig. 6).

The intensities in the different parts of the SSI observation can be expressed as

$I_{\text {left }}=13.8$ s $F_{1 \mathrm{MC}}$,

$I_{\text {streak }}=t_{\text {scan }} F_{1 \mathrm{MC}}$,

$I_{\text {right }}=\left(25.6 \mathrm{~s}-\left(13.8 \mathrm{~s}+t_{\mathrm{scan}}\right)\right) F_{1 \mathrm{MC}}+6.4 \mathrm{~s} F_{\mathrm{CLR}}$,

$R=F_{\mathrm{CLR}} / F_{1 \mathrm{MC}}$,

where $I_{\text {left }}$ is the intensity on the left (expressed in electrons), $F_{1 \mathrm{MC}}$ is the flux through the $1 \mathrm{MC}$ filter (expressed in electrons $/ \mathrm{s}), I_{\text {streak }}$ is the intensity of the streak, $t_{\text {scan }}$ is the duration of the scan, $I_{\text {right }}$ is the intensity on the right, and $F_{\mathrm{CLR}}$ is the flux through the CLR filter. $I_{\text {left }}$ could not be measured

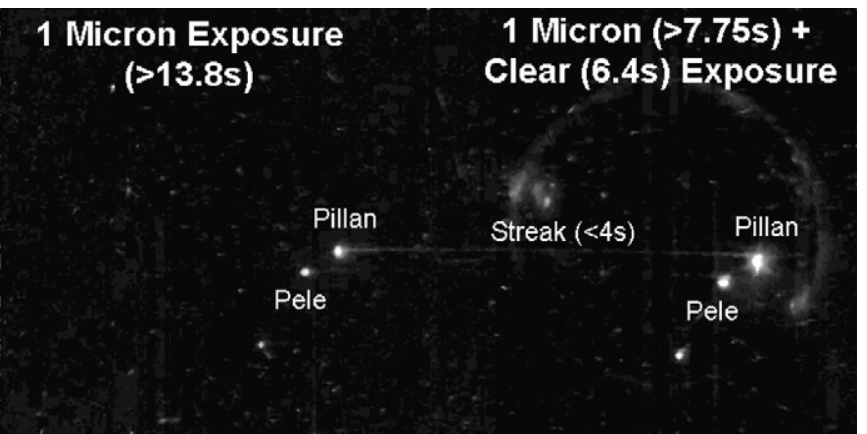

Fig. 6. SSI observation of the extreme temperature eruption at Pillan Patera. This observation was intended to be a double exposure with the data taken through the 1-micron filter on the left and through the clear filter on the right. It suffered from a sequencing error that moved the scan platform during the $1 \mathrm{mi}$ cron exposure, producing a bright streak connecting the two Pillan bright spots. The Pillan bright spots are saturated, complicating attempts to quantify their brightness. Other eruptions (including Pele), auroral glows, radiation noise, and compression artifacts are also visible in this image.

because the bright spot on the left is saturated. However, the streak is not saturated and McEwen et al. (1998b) estimated $I_{\text {streak }}$ to be $99,000 \pm 15,000 \mathrm{e}^{-}$. While the spot on the right is saturated, it is so overexposed that it is bleeding. Bleeding is a moderately well quantified process, allowing McEwen et al. (1998b) to estimate $I_{\text {right }}$ at $2.6 \times 10^{6}-6.3 \times 10^{6} \mathrm{e}^{-} \cdot t_{\text {scan }}$ was expected to be $4 \mathrm{~s}$, giving an $R$ between 13.4 and 45.4 for Pillan. It should be noted that there are auroral glows associated with many volcanic plumes on Io (Geissler et al., 2001, 2004). However, the plausible intensity for the Pillan plume is negligible when compared to the observed thermal emission (McEwen et al., 1998b).

Our first step was to re-examine the analysis of $I_{\text {right }}$ presented in McEwen et al. (1998b). We examined the radial profile in brightness away from the center of the Pillan bright spot in the right-hand side of the image and fit a curve to this profile (Fig. 7). Because there are so few pixels to work with, a statistical analysis of the uncertainties of this fit is not particularly meaningful. Instead, the uncertainties in $I_{\text {right }}$ are dominated by the fact that the size of the center of the bright spot may be either $1 \times 1$ pixels or $2 \times 2$ pixels. This is because the intensity drops exponentially away from the center so the results are not sensitive to the details of the fit away from the center. It should be explicitly stated that this fit is just an attempt to arrive at a reasonable value. It is not an analysis that takes into account the smear induced by the unsteadiness of the scan platform or the point spread function of the optics. In the end, we agree with McEwen et al. (1998b) that $I_{\text {right }}$ must lie between $2.6 \times 10^{6}$ and $6.3 \times 10^{6} \mathrm{e}^{-}$, though this analysis suggests that it is most likely to be within the range of $2.8 \times 10^{6}-5.0 \times 10^{6} \mathrm{e}^{-}$. Therefore, all we have achieved by re-examining $I_{\text {right }}$ is to identify a "likely" range that is slightly more restrictive than the "possible" range determined by McEwen et al. (1998b).

The second step was to re-examine the $I_{\text {streak }}$. The scan platform motion began with constant force being applied in one direction; then the same force was applied in the opposite direction to stop the scan in the desired position. The result is that the scan platform accelerated to the midpoint of the scan, 


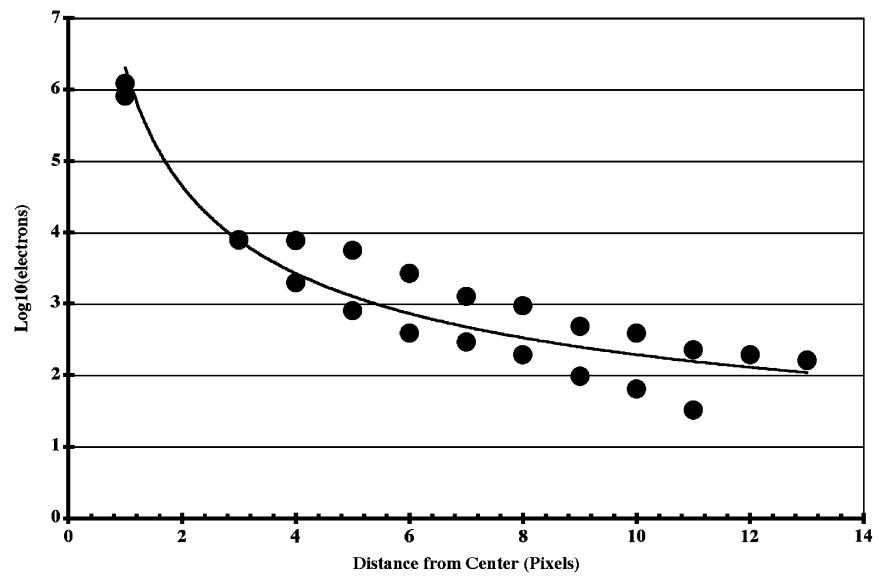

Fig. 7. Fit to bright spot on the right-hand side of the SSI image. Two profiles away from the center of the bright spot were obtained, avoiding other volcanic centers, obvious radiation noise, and large compression artifacts. Note the logarithmic scale for the $y$-axis. The best-fit signal (in electrons) is given by $10^{y}$ where $y=6.3 x^{-0.44}$ where $x$ is the distance from the center of the bright spot. Uncertainties are dominated by the fact that the "center" may span either 1 or 2 pixels.

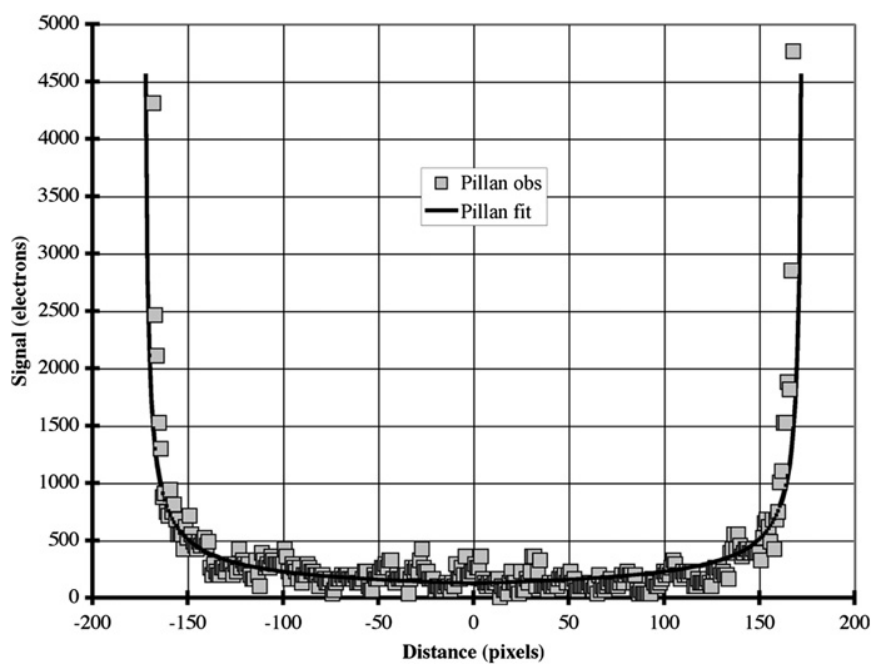

Fig. 8. Fit to the Pillan bright streak in the SSI image (Fig. 6). The observed values are obtained by summing a total of 3 pixels vertically, centered on each streak pixel, and subtracting an average background value. The empirical fit attempts to duplicate the shape of the curve expected from our understanding of how the scan platform mechanism operated. The best-fit signal(in electrons) is given by $4450(172-|x|)^{-0.7}$, where $x$ is the distance from the center of the streak.

then decelerated, and the intensity of the streak was inversely proportional to scan speed (Fig. 8). We find that a significant part of the streak's signal is hidden under the bright spots at either end. We now estimate that $I_{\text {streak }}$ is $\sim 117,000 \mathrm{e}^{-}$with an uncertainty of $\sim 10 \%$. The lower bound of this new analysis just overlaps with the upper bound of McEwen et al. (1998b), which is to be expected since we are finding signal that the earlier study did not include. By raising $I_{\text {streak }}, F_{1 \mathrm{MC}}$ is also being raised, so $R$ is lowered, and the color temperature is reduced.

The final step was to use the weak constraints on $I_{\text {left }}$ to confirm the assertion that $t_{\text {scan }}$ is $4 \mathrm{~s}$. While there are saturated pixels within the bright spot on the left, $I_{\text {left }}$ must be in the range of $0.3-1.8 \times 10^{6} \mathrm{e}^{-}$. The lower value corresponds to the minimum to saturate and the maximum is just under the limit to cause bleeding (which is not observed). Using a value of $4 \mathrm{~s}$ for $t_{\text {scan }}$ yields $0.4 \times 10^{6} \mathrm{e}^{-}$for $I_{\text {left }}$, which is within the allowable range and close to the lower limit. This fits with the qualitative impression that the spot on the left is not badly saturated.

With these new values, $R$ is calculated to be in the range of 12.4-28.5. The likely range for the CLR/1MC ratio has been cut almost in half, but more importantly, the lower limit has dropped by 1 . The SSI data now allow a color temperature as low as $1180^{\circ} \mathrm{C}$ with a corresponding eruption temperature of $1340^{\circ} \mathrm{C}$.

However, it was the combination of NIMS and SSI data that provided the tightest constraints on eruption temperature (Davies et al., 2001). The emplacement model used by Davies et al. (2001) consisted of two components, each with a different distribution of temperatures and areas. The first (hotter) component consisted of an area of only $9 \mathrm{~km}^{2}$, with temperatures from 1597 to $\sim 630^{\circ} \mathrm{C}$. This represented the thermal emission from the lava fountains. The second component comprised of extensive lava flows, with a temperature range from a maximum of 1597 to about $127^{\circ} \mathrm{C}$. Thermal emission from the areas of both components above $427^{\circ} \mathrm{C}$ (the theoretical temperature detection limit for SSI), were used to synthesize the SSI CLR/1MIC ratio. The temperature of $1597^{\circ} \mathrm{C}$ was the minimum temperature to fit a CLR/1MIC ratio of 13.4. With the new ratio of 12.4, Fig. 7 of Davies et al. (2001) shows that the combined SSI and NIMS data can be fitted with an eruption temperature close to $1500^{\circ} \mathrm{C}$, still indicative of magma of ultramafic composition.

However, like other earlier studies, the Davies et al. (2001) analysis applied a lava flow thermal model (Davies, 1996) to lava fountains. While the longer wavelength NIMS data may be less sensitive than SSI to the choice of thermal emission model, the high temperature component from Davies et al. (2001) relies primarily on the shortest NIMS wavelengths. In fact, almost all of the thermal emission detected at wavelengths shorter than $2.5 \mu \mathrm{m}$ by NIMS in the Pillan 1997 eruption was from the lava fountain component, as thermal emission from the flows is dominated by relatively cool crust. Additional work is therefore needed to model the Pillan combined SSI-NIMS dataset, this time utilizing both the lava fountain and lava flow thermal emission models to better comprehend the relationship between temperature distribution and synthesis of the SSI CLR/1MIC ratio. For now, the lower limit on eruption temperature at Pillan is $1340^{\circ} \mathrm{C}$.

\section{Conclusion}

We have eliminated the $\sim 300^{\circ} \mathrm{C}$ discrepancy between theory and observation, but the analysis retains an uncertainty of order $\sim 100^{\circ} \mathrm{C}$. The highest lower limit on eruption temperatures on Io is now $\sim 1340^{\circ} \mathrm{C}$ while the theoretical limit from interior models is $\sim 1450^{\circ} \mathrm{C}$ to which $\sim 50^{\circ} \mathrm{C}$ is predicted to be added by viscous dissipation during magma ascent. To bring the interior models and observed eruption temperatures in alignment, we suggest that (a) Io's uppermost mantle contains a very large fraction of melt (probably 20-30 vol\%) and is mechani- 
cally very weak, (b) ascent of magma through the compressive regime of the ionian lithosphere leads to significant superheating, and (c) lava fountains play a major role in controlling the thermal flux that we observe from high-temperature eruptions on Io.

A more complete model for the thermal flux from lava fountains is the single most important next step in continuing to refine our understanding of ionian volcanism and the interior of this bizarre world. Other areas in need of further investigation are (i) magma transport and other igneous processes within the mantle, (ii) the interaction between the cold lithosphere and hot asthenosphere, (iii) the effect of compressible gases on the superheating during ascent, and (iv) improved quantification of the uncertainties in the NIMS and SSI data. Although much work remains, a plausible model for the interior of Io that is consistent with the observational constraints is finally emerging.

\section{Acknowledgments}

This work was conducted with funding from the NASA Planetary Geology and Geophysics and Outer Planets Research Programs. We thank Paul Geissler, Jeff Byrnes, Bob Howell, and Julie Rathbun for their very helpful reviews. Part of this work was carried out at the Jet Propulsion LaboratoryCalifornia Institute of Technology, under contract to NASA.

\section{References}

Anderson, J.D., Jacobson, R.A., Lau, E.L., Moore, W.B., Schubert, G., 2001. Io's gravity field and interior structure. J. Geophys. Res. 106, 32963-32969.

Asimow, P.D., Ghiorso, M.S., 1998. Algorithmic modifications extending MELTS to calculate subsolidus phase relations. Am. Mineral. 83, 11271131.

Blaney, D.L., Johnson, T.V., Matson, D.L., Veeder, G.J., 1995. Volcanic eruptions on Io: Heat flow, resurfacing, and lava composition. Icarus 113, 220 225.

Consolmagno, G.J., 1981. Io: Thermal models and chemical evolution. Icarus 47, 36-45.

Davies, A.G., 1996. Io's volcanism: Thermophysical models of silicate lava compared with observations of thermal emission. Icarus 124, 45-61.

Davies, A.G., Keszthelyi, L.P., Williams, D.A., Phillips, C.B., McEwen, A.S., Lopes, R.M.C., Smythe, W.D., Kamp, L.W., Soderblom, L.A., Carlson, R.W., 2001. Thermal signature, eruption style, and eruption evolution at Pele and Pillan on Io. J. Geophys. Res. 106, 33079-33104.

Fischer, H.-J., Spohn, T., 1990. Thermal-orbital histories of viscoelastic models of Io (J1). Icarus 83, 39-65.

Geissler, P.E., McEwen, A.S., Keszthelyi, L., Lopes-Gautier, R., Granahan, J., Simonelli, D.P., 1999. Global color variations on Io. Icarus 140, 265-282.

Geissler, P.E., Smyth, W.H., McEwen, A.S., Ip, W., Belton, M.J.S., Johnson, T.V., Ingersoll, A.P., Rages, K., Hubbard, W., Dessler, A.J., 2001. Morphology and time variability of Io's visible aurora. J. Geophys. Res. 106 26137-26146.

Geissler, P., McEwen, A., Porco, C., Strobel, D., Saur, J., Ajello, J., West, R., 2004. Cassini observations of Io's visible aurorae. Icarus 172, 127-140.

Ghiorso, M.S., Sack, R.O., 1995. Chemical mass transfer in magmatic processes. IV. A revised and internally consistent thermodynamic model for the interpolation and extrapolation of liquid-solid equilibria in magmatic systems at elevated temperatures and pressures. Contrib. Mineral. Petrol. 119, 197-212.

Hopper, R.W., Onorato, P., Uhlmann, D.R., 1974. Thermal histories and crystal distributions in partly devitrified lunar glasses cooled by radiation. Proc. Lunar Sci. Conf. 5, 2257-2273.
Howell, R.R., 1997. Thermal emission from lava flows on Io. Icarus 127, 394 407.

Jaeger, W.L., Davies, A.G., 2006. Models for the crustal structure of Io: Implications for magma dynamics. Lunar Planet. Sci. 37. Abstract \#2274.

Jaeger, W.L., Turtle, E.P., Keszthelyi, L.P., Radebaugh, J., McEwen, A.S., Pappalardo, R.T., 2003. Orogenic tectonism on Io. J. Geophys. Res. 108, doi:10.1029/2002JE001946.

Johnson, T.V., Cook II, A.F., Sagan, C., Soderblom, L.A., 1979. Volcanic resurfacing rates and implications for volatiles on Io. Nature 280, 746-750.

Kargel, J.S., and 23 colleagues, 2003. Extreme volcanism on Io: Latest insights at the end of the Galileo Era. Eos 84, 313-318.

Kelemen, P.B., Hirth, G., Shimizu, N., Spielgelman, M., Dick, H.J.B., 1997. A review of melt migration processes in the adiabatically upwelling mantle beneath oceanic spreading ridges. Philos. Trans. R. Soc. Lond. A 335, $283-$ 318.

Keszthelyi, L., McEwen, A., 1997a. Magmatic differentiation of Io. Icarus 130, 437-448.

Keszthelyi, L., McEwen, A., 1997b. Thermal models for basaltic volcanism on Io. Geophys. Res. Lett. 24, 2463-2466.

Keszthelyi, L., McEwen, A.S., Taylor, G.J., 1999. Revisiting the hypothesis of a mushy global magma ocean in Io. Icarus 141, 415-419.

Keszthelyi, L., Jaeger, W.L., Turtle, E.P., Milazzo, M., Radebaugh, J., 2004. A post-Galileo view of Io's interior. Icarus 169, 271-286.

Klein, L.C., Uhlmann, D.R., 1976. The kinetics of lunar glass formation, revisited. Proc. Lunar Sci. Conf. 7, 1113-1121.

Kohlstedt, D.L., Zimmerman, M.E., 1996. Rheology of partially molten mantle rocks. Annu. Rev. Earth Planet. Sci. 24, 41-62.

Kuskov, O.L., Kronrod, V.A., 2001. Core sizes and internal structure of the Earth's and Jupiter's satellites. Icarus 151, 204-227.

Lewis, J.S., 1982. Io: Geochemistry of sulfur. Icarus 50, 103-114

Lopes-Gautier, R., and 12 colleagues, 1999. Active volcanism on Io: Global distribution and variations in activity. Icarus 140, 243-264.

Lopes, R.M.C., and 14 colleagues, 2001. Io in the near infrared: Near-Infrared Mapping Spectrometer (NIMS) results from the Galileo flybys in 1999 and 2000. J. Geophys. Res. 106, 33053-33078.

Lopes, R.M.C., and 10 colleagues and the Galileo NIMS and SSI Teams, 2004. Lava lakes on Io: Observations of Io's volcanic activity from Galileo NIMS during the 2001 flybys. Icarus $169,140-174$.

Marsh, B.D., 1981. On the crystallinity, probablility of occurrence, and rheology of lava and magma. Contrib. Mineral. Petrol. 78, 85-98.

McEwen, A.S., Matson, D.L., Johnson, T.V., Soderblom, L.A., 1985. Volcanic hot spots on Io: Correlation with low-albedo calderas. J. Geophys. Res. 90, 12345-12379.

McEwen, A.S., Simonelli, D., Senske, D., Klaasen, K., Keszthelyi, L., Johnson, T., Geissler, P., Carr, M., Belton, M., 1997. High-temperature hot spots on Io as seen by the Galileo Solid State Imaging (SSI) experiment. Geophys. Res. Lett. 24, 2443-2446.

McEwen, A.S., and 13 colleagues, 1998a. Active volcanism on Io as seen by Galileo SSI. Icarus 135, 181-219.

McEwen, A.S., and 14 colleagues, 1998b. High-temperature silicate volcanism on Jupiter's moon Io. Science 281, 87-90.

McEwen, A.S., and 25 colleagues, 2000. Galileo at Io: Results from highresolution imaging. Science 288, 1193-1198.

McKay, D.S., Heiken, G.H., Waits, G., 1978. Core 74001/2: Grain size and petrology as the key to the rate of in-situ reworking and lateral transport on the lunar surface. Proc. Lunar Sci. Conf. 9, 1913-1932.

McKinnon, W.B., 2004. On the oxidation states of the Galilean satellites: Implications for internal structures, ocean chemistry, and magnetic fields. Lunar Planet. Sci. 35. Abstract \#2137.

Milazzo, M.P., Keszthelyi, L.P., Radebaugh, J., Davies, A.G., Turtle, E.P., Geissler, P., Klaasen, K.P., Rathbun, J.A., McEwen, A.S., 2005. Volcanic activity at Tvashtar Catena, Io. Icarus 179, 235-251.

Monnereau, M., Dubuffet, F., 2002. Is Io's interior really molten? Icarus 158, 450-459.

Moore, W.B., 2001. The thermal state of Io. Icarus 154, 548-550.

Moore, W.B., 2003. Tidal heating and convection in Io. J. Geophys. Res. 108, doi:10.1029/2002JE001943.

O'Reilly, T.C., Davies, G.F., 1981. Magma transport of heat on Io: A mechanism allowing a thick lithosphere. Geophys. Res. Lett. 8, 313-316. 
Pinkerton, H., Stevenson, R., 1992. Methods for determining the rheological properties of lavas from their physico-chemical properties. J. Volcanol. Geotherm. Res. 53, 47-66.

Radebaugh, J., Keszthelyi, L.P., McEwen, A.S., Turtle, E.P., Jaeger, W., Milazzo, M., 2001. Paterae on Io: A new type of volcanic caldera? J. Geophys. Res. 106, 33005-33020.

Radebaugh, J., McEwen, A.S., Milazzo, M.P., Keszthelyi, L.P., Davies, A.G., Turtle, E.P., Dawson, D.D., 2004. Observations and temperatures of Io's Pele Patera from Cassini and Galileo spacecraft images. Icarus 169, 65-79.

Ross, M.N., Schubert, G., 1985. Tidally forced viscous heating in a partially molten Io. Icarus 64, 391-400.

Schaefer, L., Fegley Jr., B., 2004. A thermodynamic model of high temperature lava vaporization on Io. Icarus 169, 216-241.

Schenk, P.M., Bulmer, M.H., 1998. Origin of mountains on Io by thrust faulting and large-scale mass movements. Science 279, 1514-1517.

Schenk, P., Hargitai, H., Wilson, R., McEwen, A., Thomas, P., 2001. The mountains of Io: Global and geological perspectives from Voyager and Galileo. J. Geophys. Res. 106, 33201-33222.

Segatz, M., Spohn, T., Ross, M.N., Schubert, G., 1988. Tidal dissipation, surface heat flow, and figure of viscoelastic models of Io. Icarus 75, 187-206.
Simkin, T., Siebert, L., 1994. Volcanoes of the World. Geoscience Press, Tucson, $368 \mathrm{pp}$.

Solomatov, V.S., 2000. Fluid dynamics of a terrestrial magma ocean. In: Ringwood, A.E. (Ed.), Origin of the Earth and Moon. Springer-Verlag, New York, pp. 323-338.

Spencer, J.R., Schneider, N.M., 1996. Io on the eve of the Galileo Mission, Annu. Rev. Earth Planet. Sci. 24, 125-190.

Stansberry, J.A., Spencer, J.R., Howell, R.R., Dumas, C., Vakil, D., 1997. Violent silicate volcanism on Io in 1996. Geophys. Res. Lett. 24, 2455-2458.

Veeder, G.J., Matson, D.L., Johnson, T.V., Blaney, D.L., Goguen, J.D., 1994 Io's heat flow from infrared photometry: 1983-1993. J. Geophys. Res. 99, 17095-17162.

Williams, D.A., Davies, A.G., Keszthelyi, L.P., Greeley, R., 2001. The summer 1997 eruption at Pillan Patera on Io: Implications for ultrabasic lava flow emplacement. J. Geophys. Res. 106, 33105-33119.

Wilson, L., Head, J.W., 2001. Lava fountains from the 1999 Tvashtar Catena fissure eruption on Io: Implications for dike emplacement mechanisms, eruption rates, and crustal structure. J. Geophys. Res. 106, 32997-33004.

Zimmerman, M.E., Kohlstedt, D.L., 2004. Rheologic properties of partially molten lherzolite. J. Petrol. 45, 275-298. 